Submitted to IEEE Transactions on Plasma Science

Special Issue on Imaging in Plasma Science

to be published in June 2011

\title{
A Plasma Lens for Magnetron Sputtering
}

\author{
André Anders, Fellow, IEEE, and Jeff Brown
}

A. Anders is with the Lawrence Berkeley National Laboratory, University of California, 1 Cyclotron Rd., Berkeley, CA 94720, email aanders@lbl.gov. J. Brown is with Acree Technologies, Inc., 1980 Olivera Rd. Suite D, Concord, CA 94520, email jbrown@acreetech.com.

Manuscript November 30, 2010

\section{ACKNOWLEDGMENT}

Work at Berkeley Lab was supported by the U.S. Department of Energy, and under Contract No. DEAC02-05CH11231.

\section{DISCLAIMER}

This document was prepared as an account of work sponsored by the United States Government. While this document is believed to contain correct information, neither the United States Government nor any agency thereof, nor The Regents of the University of California, nor any of their employees, makes any warranty, express or implied, or assumes any legal responsibility for the accuracy, completeness, or usefulness of any information, apparatus, product, or process disclosed, or represents that its use would not infringe privately owned rights. Reference herein to any specific commercial product, process, or service by its trade name, trademark, manufacturer, or otherwise, does not necessarily constitute or imply its endorsement, recommendation, or favoring by the United States Government or any agency thereof, or The Regents of the University of California. The views and opinions of authors expressed herein do not necessarily state or reflect those of the United States Government or any agency thereof or The Regents of the University of California. 


\title{
A Plasma Lens for Magnetron Sputtering
}

\author{
André Anders, Fellow, IEEE, and Jeff Brown
}

A. Anders is with the Lawrence Berkeley National Laboratory, University of California, 1 Cyclotron Rd., Berkeley, CA 94720, email aanders@1bl.gov. J. Brown is with Acree Technologies, Inc., 1980 Olivera Rd. Suite D, Concord, CA 94520, email jbrown@acreetech.com.

Work was supported by the U.S. Department of Energy under Contract No. DE-AC02-05CH11231.

\begin{abstract}
A plasma lens, consisting of a solenoid and potential-defining ring electrodes, has been placed between a magnetron and substrates to be coated. Photography reveals qualitative information on excitation, ionization, and the transport of plasma to the substrate.
\end{abstract}

Magnetron sputtering is a widely used coatings technology [1]. In essence, a magnetically enhanced glow discharge with closed electron drift is operated at relatively low pressure, of order $1 \mathrm{~Pa}$, such that the cathode of the discharge is "targeted" by positive ions. Surface atoms of the cathode (target) are removed and used for the deposition of thin films and coatings. Several distinct versions of magnetron sputtering have been developed over the years, and in particular high power impulse magnetron sputtering (HIPIMS) is a much talked-about new addition to the family of sputtering technologies for the deposition of thin films [2].

In reactive deposition, the magnetron is operated in a mixture of noble gas (usually argon) and reactive gas, such as oxygen in case an oxide coating is desired. For example, aluminum-doped zinc oxide, AZO [3], is a recently much researched transparent conducting oxide (TCO) because it is a low cost alternative to the more costly indium-tin-oxide (ITO) widely used in displays, solar cells, light emitting diodes, etc.

The electric field that accelerates positive ions to the target also accelerates negative ions away from the target towards the substrate. Reactive deposition with oxygen implies that negative oxygen ions are present, and therefore, apparently unavoidable, the growing film is subject to bombardment of high energy $(>100 \mathrm{eV})$ negative ions, causing "ion damage" [4], which is highly undesirable for some crystalline films such as TCOs.

A magnetron produces plasma of gas (and in the case of HIPIMS also of the target metal). A portion of the plasma can escape from the magnetron depending on the unbalancing of the magnetic field. Stronger unbalancing is used to intentionally assist film growth by (positive) ions of relative low energy (most $<20 \mathrm{eV}$ ).

Fig. 1 shows an interesting approach to plasma utilization in magnetron sputtering. Here, a solenoid generates an essentially axial magnetic field which influences the degree of unbalancing the magnetron, promoting the escape of plasma. Apart from affecting the magnetic field near the target zone, the solenoid also aids the excitation and ionization of material, and guides the plasma to the substrate. That is, while electrons and positive ions are confined and transported, negative ions are actually pushed out of the plasma stream: in this sense the solenoid acts as a plasma lens with focusing properties for positive ions and defocusing for negative ions [5-7]. The guiding of plasma by solenoids has been much studied for filtered cathodic arc plasma deposition [8-9]; and the field of research has been dubbed plasma optics [10]. An image of arc plasma transport in a curved solenoid filter has been shown in one of the previous Special Issues on Images in Plasma Science [11]. In cathodic arcs, the motivation was to rid the plasma of the undesired so-called macroparticles. In HIPIMS, an axial magnetic field was shown to locally enhance the deposition rate [12]. Here, however, a main goal is to affect the ratio of positive and negative ions arriving on the substrate. The plasma lensing effect is based on the radial electric field that builds when electrons are magnetized by ions are not. One can go one step further and introduce ring electrodes near the solenoid's entrance and exit to aid in establishing a desired potential gradient. A curved version of such plasma lens has the advantage of also addressing macroparticle issues in case arcing occurs though the deposition rate is reduced.

The photo of Fig. 1 was taken through a window of the vacuum processing chamber using a Canon EOS Rebel T1i SRL camera with a 15 megapixel CMOS detector. The exposure time was $1 / 30 \mathrm{~s}$, with $\mathrm{f} / 5$ aperture, at a sensitivity of ISO 1600. In the center part of the figure we see a coil made of $1 / 4$ " copper tubing, which is water-cooled. Biasable electrode rings are placed near the entrance and exit of the solenoid. The 2-inch $(5 \mathrm{~cm})$ diameter planar magnetron, shown on the right, with a 2" $(5 \mathrm{~cm})$ diameter Zn4at\%Al target was connected to a Pinnacle Plus magnetron supply (Advanced Energy). The mediumfrequency discharge was run with $300 \mathrm{~W}$ average power, at $315 \mathrm{~V}$ and $0.95 \mathrm{~A}, 150 \mathrm{kHz}$, with a $0.5 \mu$ s reverse phase. The gas flow ratio of argon and oxygen was 30:9 resulting in a pressure of $0.53 \mathrm{~Pa}$ during deposition. The solenoid carried $400 \mathrm{~A}$ of current. The AZO films made at $200^{\circ} \mathrm{C}$ were of good quality with a transmission of about $85 \%$ in the visible spectrum, and an electrical conductivity in the high $10^{-4} \Omega \mathrm{cm}$. Using HIPIMS and a 90-degree filter delivered even better films with $3.5 \times 10^{-4}$ 
$\Omega \mathrm{cm}$ at a reduced substrate temperature of only $160^{\circ} \mathrm{C}$, to be reported elsewhere. Research in the lensing effect and film optimization are still ongoing.

Technical support by Joe Wallig is gratefully acknowledged.

\section{REFERENCES}

[1] P. Martin, Ed., Handbook of Deposition Technologies for Films and Coatings (Norwich, NY: William Andrew, 2009).

[2] K. Sarakinos, J. Alami, and S. Konstantinidis, "High power pulsed magnetron sputtering: Scientific and engineering state of the art," Surf. Coat. Technol., vol. 204, pp. 1661-1684, 2010.

[3] K. Ellmer, A. Klein, and B. Rech, Eds., Transparent Conductive Zinc Oxide: Basics and Applications in Thin Film Solar Cells (New York: Springer, 2008).

[4] S. Mráz and J. M. Schneider, "Influence of the negative oxygen ions on the structure evolution of transition metal oxide thin films," J. Appl. Phys., vol. 100, pp. 023503-6, 2006.

[5] A. Anders, "LBNL patent disclosure IB-2473, July 13, 2007: Method and apparatus for improved high power impulse magnetron sputtering" (unpublished).

[6] A. Anders and J. Brown, "LBNL disclosure IB-2712, Method and Apparatus for Filtered High Power Impulse Magnetron Sputtering", March 13, 2009 (unpublished)

[7] A. Anders, LBNL disclosure IB-2803: "Method and Apparatus for Sputtering with a Plasma Lens", December 7, 2009 (unpublished).

[8] I. I. Aksenov, V. G. Padalka, V. T. Tolok, and V. M. Khoroshikh, "Motion of plasma streams from a vacuum arc in a long, straight plasma optics system," Sov. J. Plasma Phys., vol. 6, pp. 504-507, 1980.

[9] A. Anders, Cathodic Arcs: From Fractal Spots to Energetic Condensation. New York: Springer, 2008.

[10] A. I. Morozov and S. V. Lebedev, "Plasma Optics," in Reviews of Plasma Physics, Vol. 8, M. A. Leontovich, Ed., New York: Consultants Bureau, 1980, pp. 301-460.

[11] A. Anders, "Imaging the separation of cathodic arc plasma and macroparticles in curved magnetic filters," IEEE Trans. Plasma Sci., vol. 30, pp. 108-109, 2002.

[12] J. Bohlmark, M. Ostbye, M. Lattemann, H. Ljungcrantz, T. Rosell, and U. Helmersson, "Guiding the deposition flux in an ionized magnetron discharge," Thin Solid Films, vol. 515, pp. 1928-1931, 2006.

\section{Figure Caption}

Fig. 1. A plasma lens placed between magnetron (right) and substrate (left). The magnetron has a 2 -inch $(5 \mathrm{~cm})$ diameter aluminum-doped zinc target, operating in an argon-oxygen gas mixture. Microscope slide substrates are mounted on a heater; the goal is to deposit high quality aluminum-doped zinc oxide films, a low-cost transparent conductor. 


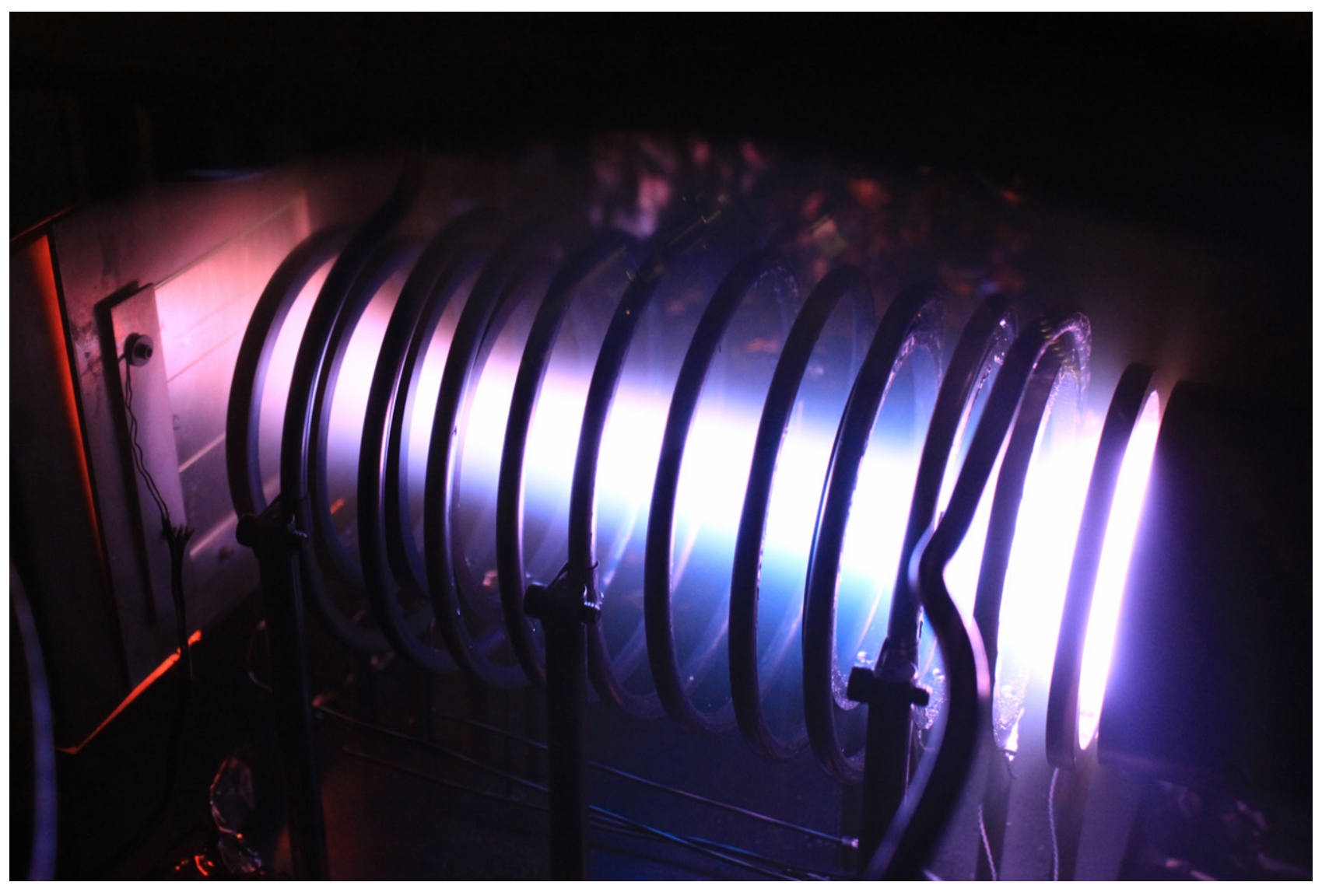

Fig. 1 